\title{
Customer Care Excellence in the New Product Development Process: A Case Study
}

\author{
* Kerttu Saalasti Institute, \\ University of Oulu, \\ FI-85500, Finland \\ Industrial Engineering and Management \\ University of Oulu \\ P.O. Box 4610 \\ FI-90014, Finland \\ E-mail: ville.isoherranen@oulu.fi \\ E-mail: jukka.majava@oulu.fi \\ *Corresponding author
}

Ville Isoherranen* and Jukka Majava

\begin{abstract}
Excellence in product development can be achieved by integrating various stakeholders' requirements into a winning offering. After-market services have become increasingly important for companies, as digitalisation enables new business models and revenue streams. The integration of customer care must be performed in the product development (PD) process in the early concepting and development phases in order to ensure an excellent customer experience. The traditional elements of care-spare parts, service tools, and support-must be coupled with new services. Future cutting-edge products demand new self-support, repair, and upgrade capabilities that are enabled by the digitalisation of product-service assets and low-cost distribution platforms. This study aims to increase knowledge on how care capabilities can be created in the PD by analysing the critical care inputs and their effects in the product concepting phase. In addition, the critical care outputs in the case company's product development process in the main phases are presented.
\end{abstract}

Keywords: customer care, design for care (DfC), design for excellence (DfX), digitalisation, new product development (NPD)

Reference to this paper should be made as follows: Isoherranen, V. and Majava, J. (201X) 'Customer Care Excellence in the New Product Development Process: A Case Study', Int. J. of X, Vol. XX, No. YY, pp.XXX-XXX.

Biographical notes: Dr. Ville Isoherranen (D.Sc. (Tech.)) is the director of an international research institute, Kerttu Saalasti Institute (KSI), at the University of Oulu. $\mathrm{He}$ has an extensive international and cross-functional industrial management experience, for example, from sales and marketing, supply chain management (aftersales services, sourcing), and management consulting. Dr. Isoherranen's research interests are strategic management, operational excellence, and customer-focused enterprises.

Jukka Majava (Dr Sc) is an adjunct professor and a university lecturer in Industrial Engineering and Management at the University of Oulu, Finland. His industrial 
experience includes technology and ecosystem marketing, partner and project management, and business and supply chain development at Nokia Corporation. He has research interests in product innovation, business networks and supply chain development.

This paper is a revised and expanded version of a paper entitled 'Excellence in Integrating Care into the Product Development Process: A Case Study of Nokia,' presented at the IEEE International Conference on Industrial Engineering and Engineering Management (IEEM), 4-7 December, 2016, Bali, Indonesia.

\section{Introduction}

Digitalisation affects companies' success in the marketplace. Customers have a variety of options to fulfil their needs, and the simple transaction of buying a product is widely challenged by the service offering, which brings the capabilities of the product to the customer without the need to buy the actual product itself-instead, he or she simply consumes the service product.

Whereas customer care has not traditionally been considered to be among the most important stakeholders in product development (Majava et al., 2015), the importance of care (i.e., the activities related to post-launch maintenance, repair, support, the warranty process, and upgrading the product or service) is growing due to this transfer from one-off product sales to service sales. Care after-market services are not only the minimum compulsory activities driven by legislation or the warranty cost optimisation of sold products - they have the potential to become significant revenue streams for companies.

Design for excellence (DfX) can be considered to be a systematic way to address the needs of different stakeholders (Bralla, 1996). Some attempts have been made to study companies' DfX practices and to create a more holistic integration of the supply chain and product development (Hilletofth et al., 2010; Lopes and Bolton, 2013; Rungtusanatham and Forza, 2005). Design for care (DfC) has not been extensively studied, especially regarding the integration of care into the product development (PD) process (the focus of this study).

This study aims to increase the body of knowledge in customer care integration in PD. The paper presents a case study of the once-dominant mobile phone manufacturer Nokia, which successfully integrated care requirements and capabilities into its PD process. The focus of the analysis is on project-level activities and practices. The study is part of a larger research initiative investigating the different aspects of DfC and care capability integration into PD, business model and ecosystem development, and the implications for companies' strategic choices. This study aims to answer the following research questions (RQs):

RQ1: What are the critical care inputs to be studied in the product concepting phase, and what are their effects?

RQ2: What are the critical care outputs in the case company's product development process in the main phases? 
Customer Care Excellence in the New Product Development Process: A Case of Nokia's Mobile Phone Business

\section{Method}

This research used a single case study method. According to Yin (1989), "a case study is an empirical inquiry that investigates a contemporary phenomenon within its real-life context, when the boundaries between phenomenon and context are not evident and in which multiple sources of evidence are used." The case study is a research strategy that focuses on understanding the dynamics that are present within single settings (Eisenhardt, 1989).

The theoretical background was built on three inter-related concepts: the PD process, DfX, and DfC. The empirical data include observations and documented findings in the case company. Section 3 contains a literature review, and section 4 contains a presentation of the empirical findings and the results, and answers to the research questions. Section 5 discusses the findings, and section 6 concludes.

\section{Literature}

\subsection{Product Development and the Product Development Process}

A product can be defined as "anything referred to as an external marketplace for sale, use, or consumption. This includes physical products as well as services, and combinations of services and products" (Cooper, 2011). PD has been defined in many ways in academic literature. For instance, according to Krishnan and Ulrich (2001), PD can be defined as the "transformation of market opportunity into a product available for sale." Ulrich and Eppinger (2012), in turn, state that "product development is the set of activities beginning with perception of a market opportunity and ending in the production, sale, and delivery of a product." On the other hand, Kahn (2005) considers PD as "the overall process of strategy, organisation, concept generation, product and marketing plan creation and evaluation, and commercialisation of a new product." In this study, a broad and long-term perspective is adopted: in addition to product creation and delivery, aftermarket phase-related services are also considered.

A systematic PD process has many aims. The PD process transfers technology to a commercial application, joins technical characteristics and market needs, integrates functional efforts to create the product, implements organisation strategy through the development of a new product, and gives managerial control while not being excessively intrusive (Kahn, 2001). In spite of major differences between industries, the commonly presented linear PD model consists of eight stages: idea generation, idea screening, concept testing, business analysis, product development, test marketing, commercialisation, and monitoring and evaluation (Trott, 2012). A product plan is a typical starting point for PD. The most common process models include the waterfall model (Boehm, 1996), concurrent engineering (Krishnan and Ulrich, 2001), the iterative development model (Fujii and Kambayashi, 2012), the stage-gate model (Cooper, 2011), and the agile development model (Younker, 2008).

Whereas agile development models are increasingly popular among software companies, companies whose offerings include physical elements typically utilise stage-gate processes. Stage-gate processes can be considered to be a conceptual and operational map that guides PD projects from ideas to launch and beyond. The general flow of a stage-gate system consists of the following stages: discovery, scoping, building the business case, development, testing and validation, and launch. A gate or a go/kill decision point exist prior to each stage. In these points, the team gathers and reviews all new information. The gates serve as quality control checkpoints, as go/kill and prioritisation decision points, and points where the next steps are agreed. Gates 
include a set of required deliverables, criteria against which the project is evaluated, and clearly defined outputs, such as go/kill decisions (Cooper, 2011).

\subsection{Design for Excellence and Design for Care}

A key element for successful PD involves sufficiently fulfilling the needs of various stakeholders (Cooper, 2004; Gupta et al., 2007). DfX can be considered to be a way to address the needs of different stakeholders systematically (Bralla, 1996).

Assembly and manufacturing considerations, i.e., design for assembly (DfA) and design for manufacturability (DfM), were among the first attempts to address stakeholders' needs via DfX (Boothroyd and Dewhurst, 1983; Bralla, 1998). Since then, the use of DfX has expanded, and it is applied in various areas, including design for testability (DfT), design for environment (DfE), design for service (DfS), design for quality (DfQ), and many others (Barbosa and Carvalho, 2013; Booker, 2003; Cavalieri et al., 2007; Kurk and Eagan, 2008; Subramani and Dewhurst, 1993; Williams and Parker, 1982). The aim in the introduction of different DfXs has been to effectively consider various important aspects during PD that cover the entire product lifecycle. The DfX aspects relevant to customer care, i.e. DfC, include reliability, availability, maintainability, and the serviceability of products (Markeset and Kumar, 2003).

DfX includes techniques that range from high-level guidelines to detailed software tools. However, the use of DfX has also been criticised for resulting in an anti-holistic approach, as each element of DfX focuses on only one aspect. The number of elements can many times be vast. According to Holt and Barnes (2010), the aforementioned makes it difficult to take every requirement into account. A few attempts have been made to study companies' DfX practices and create a more holistic integration of the supply chain and PD (Hilletofth, et al., 2010; Lopes and Bolton, 2013; Rungtusanatham and Forza, 2005). However, research focusing on how customer care is integrated into PD has remained scarce.

\section{Results: Integration of Care into Product Development at Nokia}

The case company examined in this study is the former Nokia mobile phones business. Nokia's strategy in mobile phones was oriented towards product-centricity (Isoherranen and Kess, 2011). Although Nokia did not succeed in executing and renewing its strategy during major technological disruptions (i.e., touch-based operating systems and the third-party application revolution), the company is an industry benchmark in supply chain management and integrating customer care with PD. The aforementioned claim is supported by the large number of product models and variants created by the company, as well as its annual sales volume of hundreds of millions of units.

Customer care activities in Nokia were organised under both business units and regional marketing and sales organisations. Customer care resources in business units were mainly responsible for product creation-related activities, whereas regional marketing and sales organisations took care of daily transactions with business-to-business customers (i.e., operators, distributors, and retailers), and consumers. Product support for end-users was available through Nokia's customer care contact centres. Repair-related activities were mainly handled by thousands of authorised third-party service points around the world.

Figure 1 shows a high-level view of the PD process phases used at Nokia in the years 20082010 , at which time the company was the leading mobile phone manufacturer in terms of volume. Approximately 450 million Nokia phones were sold every year, and the company's warranty population was estimated to be roughly one billion units. Although phase-specific milestones are 
Customer Care Excellence in the New Product Development Process: A Case of Nokia's Mobile Phone Business

excluded in Figure 1, the process can be considered to resemble both concurrent engineering and stage-gate processes (Cooper, 2011; Krishnan and Ulrich, 2001).

\section{Product Creation}

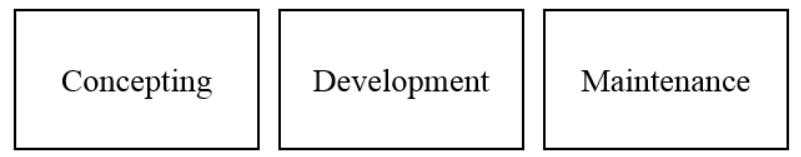

Figure 1: Product development process phases in the case company

As Figure 1 illustrates, product creation at Nokia included three distinct phases. The first phase of product creation was the concepting phase. The actual development was carried out in the development phase, which was succeeded by the maintenance phase (this takes place after product sales and deliveries have begun).

The concepting phase begins when the company's product portfolio management gives a "concepting order" for a new product. Concepting aims to address the following questions: Why? What? How? The key people participating in the concepting phase include the product programme manager (PPM), the product manager (PM), the R\&D manager, the software manager, the operations and logistics manager, the sourcing manager, and the care project manager (CPM). Different design alternatives are studied, and proposals on the following items are made: a business plan (why, or what the product aims for), product specifications (what, or what the product is like), and a product programme plan (how, or how the product will be created). The concrete deliverables in the concepting phase include sub-project product and programme briefs. For example, a care product brief describes the care and support concept for the product that will be developed and delivered to the market.

Table 1 presents 10 critical care inputs (issues) that the CPM must study and clarify in the concepting phase in order to create the care product brief (document of product care service definition, approach, and requirements) and other concepting outputs (deliverables).

Table 1: Critical care inputs in the new product development (NPD) process' concepting phase

\begin{tabular}{|l|l|l|l|l|}
\hline$\#$ & \multirow{2}{*}{ Input } & Type & $\begin{array}{c}\text { Warranty cost } \\
\text { effect }\end{array}$ & Reason(s) \\
\hline 1 & \multirow{2}{*}{\begin{tabular}{l} 
Product concept \\
\cline { 3 - 5 }
\end{tabular}} & Simple & - & $\begin{array}{l}\text { Product design and mechanical } \\
\text { structures impact failure rates, service } \\
\text { costs, and repair methods. }\end{array}$ \\
\cline { 3 - 6 } & Complex & + & & \\
\hline
\end{tabular}




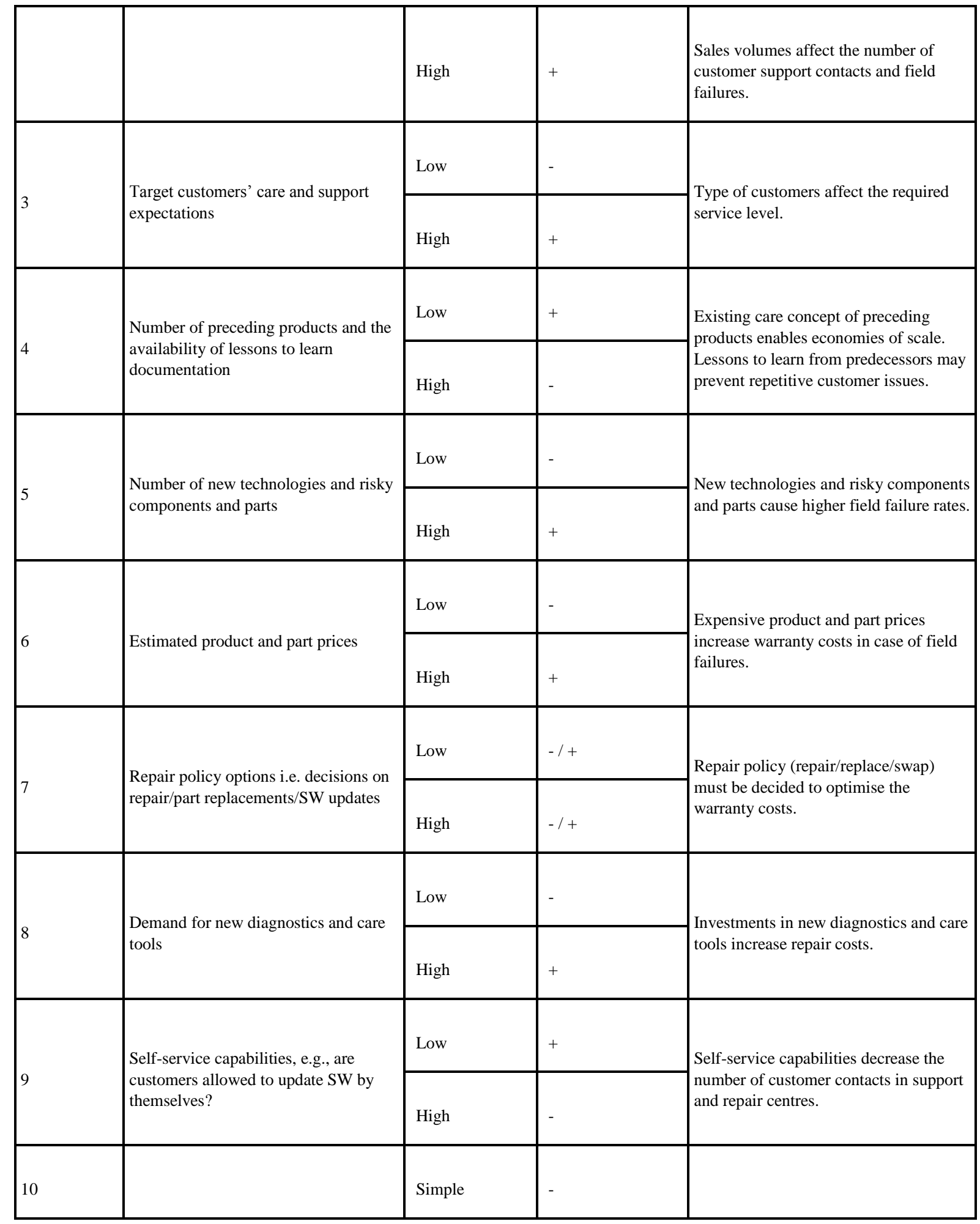


Customer Care Excellence in the New Product Development Process: A Case of Nokia's Mobile Phone Business

\begin{tabular}{|l|l|l|l|l|}
\hline & $\begin{array}{l}\text { Product and e-support arrangements, } \\
\text { i.e., how product and e-support should } \\
\text { be handled, who answers technical and } \\
\text { product support questions }\end{array}$ & Complex & + & $\begin{array}{l}\text { Some products may require extensive } \\
\text { support, training, and many escalation } \\
\text { levels, which increases warranty costs. }\end{array}$ \\
\hline
\end{tabular}

Table 1 presents the critical care concepting inputs that have been categorised based on their type, warranty cost effect, and reasoning behind categorisation. The type column categorises the input by Simple - Complex o by Low - High statements. This is then linked to the Warranty Cost effect with an increase (+) or decrease (-) of warranty costs. For example, if product concept is considered to be simple construct, it can be considered to reduce warranty costs. On the other hand, complex product concept structures can increase the warranty costs, e.g., due to more failures in the product structures during the usage of the product. This categorisation is based on the lesson learnt feedback loop from previous products, and the main aim is to avoid systematic and repeating issues in the new product concept. The CPM has a chance to affect the product concept from a DfC point of view to achieve this goal. In addition to this, in the concepting phase, it is crucial to recognise new needs (inputs) in order to avoid surprises and delays during the project.

The critical care outputs of the concepting phase are illustrated in Figure 2. Two milestones (gates), $\mathrm{C} 0$ and $\mathrm{C} 1$, and the eight key deliverables (care planning, serviceability, spare parts, product and service SW, service manual, service tools, service channel, and online support and field feedback) build the framework for the care concepting phase. In $\mathrm{C} 0$, the critical care outputs are draft care briefs and lessons learnt analysis from previous products. In $\mathrm{C} 1$, the critical care outputs are the final version of care brief with warranty cost estimation, service concept, spare parts concept, initial care software (SW) requirements for service SW and product SW, service manual and tools concept, as well as product support concept.

\section{Critical Care Outputs (O) in New Product Development (NPD) Process}
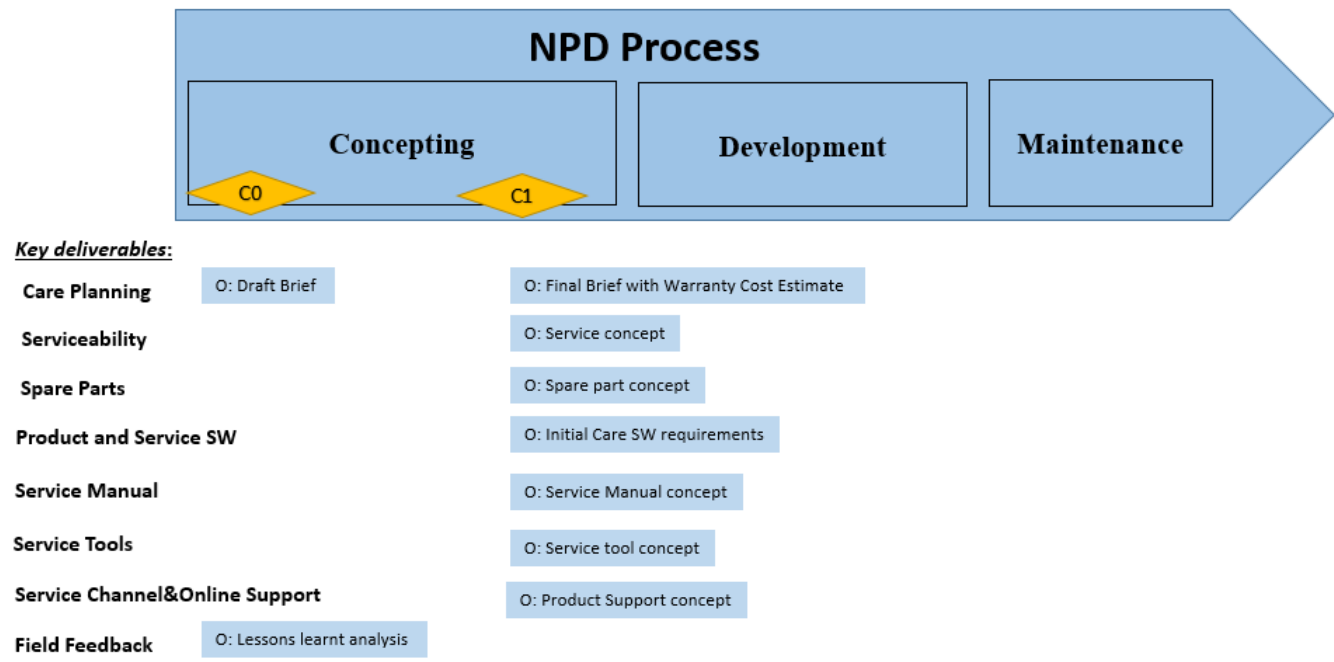
Figure 2: Critical care concepting phase outputs in new product development (NPD) process

After the concepting phase is the development phase. Typically, a product programme planning day is organised at the beginning of this phase. The participants include the product programme management team (the PPM, PM, R\&D manager, software manager, operations and logistics manager, sourcing manager, test manager, and CPM) and other sub-project representatives, such as the electro-mechanics and mechanical chief engineers. This team often conducts product programme planning by utilising a planning board and Post-it notes. Subprojects schedule their most important events and deliverables for the project, such as software requirements, production tools, user guides, specifications, layout designs, user testing, product acceptances, and prototype builds in pre-production and the factory. Figure 3 illustrates key care outputs in the development phase. The critical outputs are illustrated according to milestones (gates) D0, D1, D2, and D3.

\section{Critical Care Outputs (O) in New Product Development (NPD) Process}

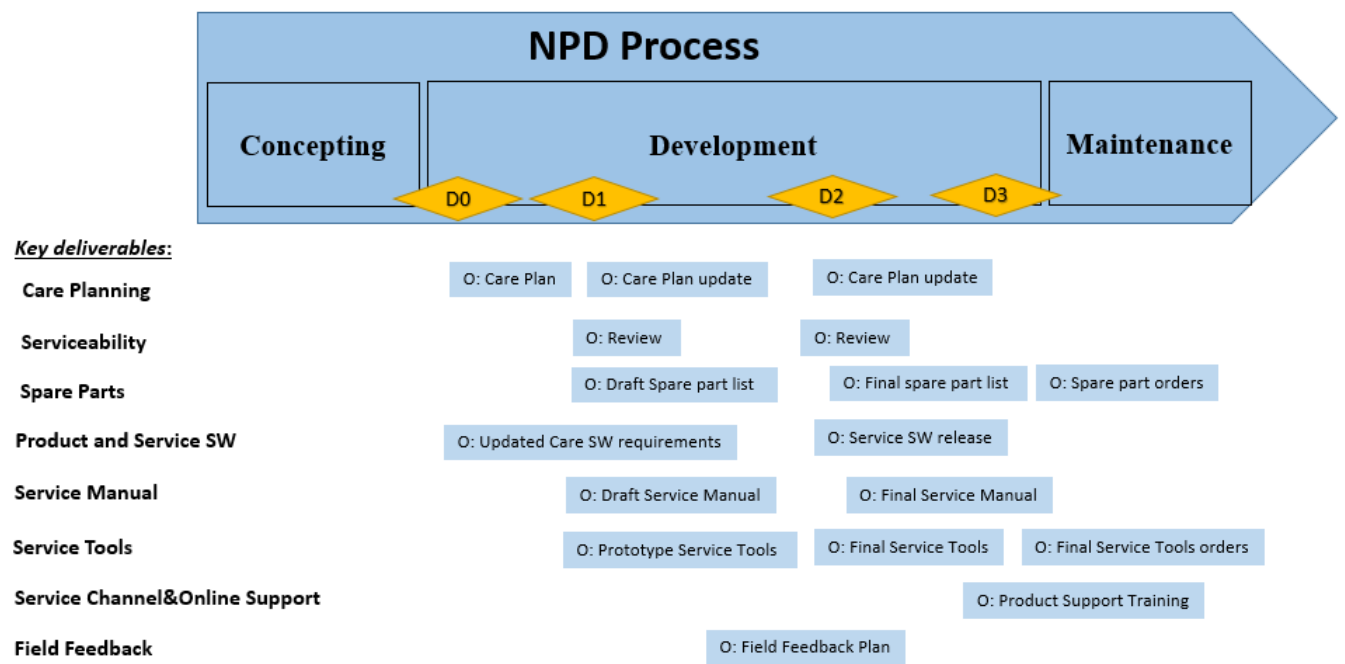

Figure 3: Critical care development phase outputs in new product development (NPD) process

From the DfC perspective, the key deliverables outputs include care software requirements, spare part list drafts and final versions, service manual drafts and final versions, product support training, service tool prototypes and final versions, and spare part orders. The team synchronises these activities by utilising the planning board and Post-it notes. For example, service tool prototypes are needed by a certain time period before the product prototype build, care software requirements by a specific date, etc. Product programme milestones are defined based on the most important events and deliverables outputs. The sales start target often drives the schedule, and activities are planned accordingly to meet this required target. In the early development phase, the CPM can and must influence the product hardware and software requirements from the customer care point of view (DfC).

The product maintenance phase starts after the production ramp-up and product sales begin. In the maintenance phase, the responsibility for the product is handed over to a product 
Customer Care Excellence in the New Product Development Process: A Case of Nokia's Mobile Phone Business

engineering (PE) team. Typical customer care-related activities in the maintenance phase include field feedback analysis via collecting a planned number of samples of the first failed products in the market, studying failure reports through customer support, and monitoring the field failure rate. The maintenance phase involves fewer R\&D resources, as these experts must be transferred to new projects. The critical care outputs in the maintenance phase are illustrated in Figure 4, according to milestones M0, M1, and M2.

Critical Care Outputs (O) in New Product Development (NPD) Process

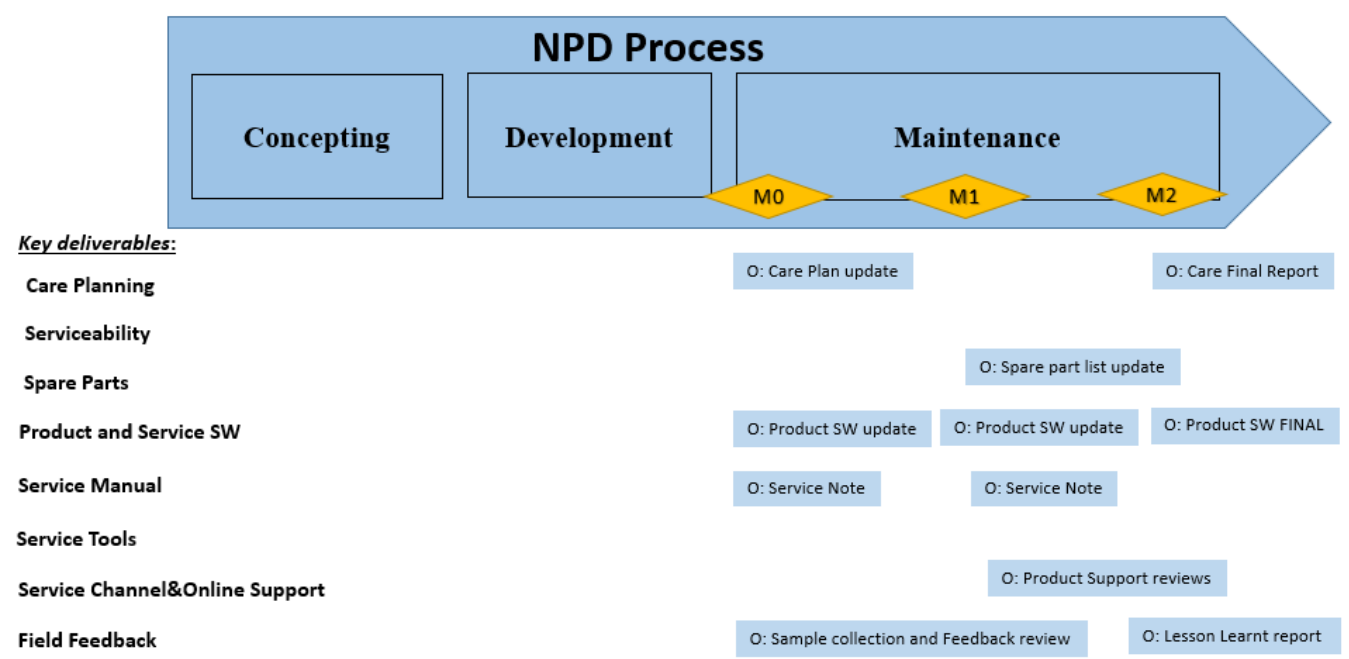

Figure 4: Critical care maintenance phase outputs in new product development (NPD) process

Unexpected product problems can appear in the product maintenance phase, such as problems related to challenging operating conditions (e.g., dust, moisture) in developing countries, software issues, and quality problems related to sensitive parts. These could include displays and new type of mechanics, especially if new technologies are involved. Customer care must identify and indicate which problems the PE team must correct by, for example, creating a new software version or changing the design, parts, components, or production process. The PE team must also monitor production yields and address possible component changes related to suppliers. Before the product ramp-down, end-of-life forecasts must be created for final products, for the related parts and components, and for spare parts.

However, the ramp-down does not equal the end of the product's lifecycle, as many customers use their products for several years. The manufacturer is also legally responsible for the product after the warranty period has expired. At this stage, care teams in sales areas remain responsible for continuing care activities and product service support. 


\section{Discussion}

This study focused on the integration of customer care into the PD process via a case study of a dominant mobile phone manufacturer. The critical care inputs and their effects, as well as critical care outputs, were analysed and presented. The research is part of a larger research initiative related to DfC and care capabilities. Based on the large number of product models and variants Nokia created and its huge market volumes, it can be considered to provide an industry benchmark.

The following theoretical and managerial implications are proposed. Regarding theoretical implications, this study complements the existing body of knowledge on PD, DfX, and DfC (e.g., Barbosa and Carvalho, 2013; Bralla, 1996; Krishnan and Ulrich, 2001) by presenting an analysis of the case company with a comprehensive integration of customer care into its product creation process. A detailed analysis of critical care inputs and outputs related to the PD process was presented in section 4 of this paper. The case company had taken a very holistic lifecycle view of PD with an aim to seamlessly integrate stakeholders' requirements into its products. Customer care was considered to be an important stakeholder in the case company's PD process, and the integration began early in the product concepting phase.

From a managerial point of view, the following implications are proposed. Although companies' daily customer care activities take place in the maintenance phase, the concepting and early development phases are vital from a DfC point of view if the company aims to succeed in the care integration into product development. If care-related requirements are not considered in the early phases of the PD process, it is very difficult to fulfil these requirements later on. Another key finding from the results of the present study was the systematic evaluation of carespecific issues in the concepting phase that were described in Table 1 . The process created by the case company enables new PD projects to take into account the key issues affecting the care concept. These key issues include, for example, the product concept, sales forecasts, and customer requirements related to care and support.

More generic and future-related observations should also be highlighted in the context of this discussion. Although it is important to identify and analyse the best practices in the industry, it should also be acknowledged that future technologies and markets will create new challenges. The ongoing digitalisation revolution will likely change delivery platforms of care services and products, as well as business models. Digitalisation is likely to disrupt the traditional and planned value networks, possibly making some of their actors obsolete. One concrete example of the recent developments in customer care is that, in many cases, customers have the capability to fix and update their products with new software features and applications without needing to interact with companies' care organisations or third-party service points. Another key trend is 3D printing, which profoundly changes how spare parts can be made available to customers. This development may remove the need to hold any physical inventory for spare parts; instead, only a digital library of drawings or printer files is needed. This information will be delivered digitally to wherever the customer is located without the need for an expensive physical delivery channel. In the future, customers may even print spare parts at their homes. Printing can also produce complex parts, which enables having almost any part of the product as a spare part.

Future developments will make the integration of care dimensions into the PD process even more important than today. It is evident that large enterprises that develop, manufacture, and sell high-volume products need to take a systematic approach to digitalisation. These companies must find an approach that enables a successful transition from their current processes to the digital era. Companies should also analyse how they can leverage new opportunities for creating revenue streams from care after-market services in the future. 
Customer Care Excellence in the New Product Development Process: A Case of Nokia's Mobile Phone Business

\section{Conclusions}

This study addressed the following research questions. RQ1: "What are the critical care inputs to be studied in the product concepting phase, and what are their effects?" RQ2: "What are the critical care outputs in the case company's product development process in the main phases?" RQ1 was answered in section 4. Results are summarised in Table 1. Ten critical care inputs were identified. These include for example: product concept, sales forecast and target customers' care and support expectations.

RQ2 was also answered in section 4, and the results are summarised in Figures 2, 3, and 4. The key deliverables are for example care plan, serviceability analysis and service tools, service SW and manuals.

The theoretical and managerial implications of the study are discussed in section 5. It can be concluded that the case company takes a very holistic and systematic approach to integrate care dimensions into its PD process. Early integration of care requirements into product development process is important. This type of approach is essential in order to ensure excellence in PD and care operations integration that can result in world-class customer service and experience. Current trends, such as digitalisation and servitization, will make the integration of care inputs into the PD process even more significant.

However, it should be stressed that the research presented in this paper includes the typical limitations of a case study, which makes generalising the results difficult. Thus, further cases should be studied in order to compare and validate the findings of the study.

In further research, it would also be important to examine care capability creation and its linkage to companies' strategic choices, as well as business models and ecosystems in the era of digitalisation. Possible approaches for future studies might include empirical analysis and conceptual research.

\section{References}

Barbosa, G.F. and Carvalho, J. (2013) 'Analytical model for aircraft design based on Design for Excellence (DFX) concepts and use of composite material oriented to automated processes', The International Journal of Advanced Manufacturing Technology, Vol. 69, No. 9-12, pp. 2333-2342.

Boehm, B. (1996) 'Anchoring the software process', IEEE Software, Vol. 13, No. 4, pp. 73-82.

Booker, J.D. (2003) 'Industrial practice in designing for quality', International Journal of Quality and Reliability Management, Vol. 20, No. 3, pp. 288-303.

Boothroyd, G. and Dewhurst, P. (1983) Design for Assembly: a Designer's Handbook, Department of Mechanical Engineering, University of Massachusetts, Amherst.

Bralla, J.G. (1996) Design for Excellence, McGraw-Hill, New York.

Bralla, J.G. (1998) Design for Manufacturability Handbook, McGraw-Hill Professional, New York.

Cavalieri, S., Gaiardelli, P. and Ierace, S. (2007) 'Aligning strategic profiles with operational metrics in after-sales service', International Journal of Productivity and Performance Management, Vol. 56, No. 5-6, pp. 436-455.

Cooper, R.G. (2004) Product Leadership, Basic Books, New York.

Cooper, R.G. (2011) Winning at New Products: Creating Value through Innovation, Basic Books, USA.

Eisenhardt, K.M. (1989) 'Building theories from case study research', The Academy of Management Review, Vol 14, No. 4, pp. 532-550. 
Fujii, T. and Kambayashi, Y. (2012), 'Strategies to suppress productivity degradation with unknown issues under iterative development process' in Proceedings of the First International Symposium on Cyber Worlds, CW 2012, pp. 121-126.

Gupta, A., Pawar, K.S. and Smart, P. (2007) 'New product development in the pharmaceutical and telecommunication industries: a comparative study', International Journal of Production Economics, Vol. 106, No. 1, pp. 41-60.

Hilletofth, P., Ericsson, D. and Lumsden, K. (2010) 'Coordinating new product development and supply chain management', International Journal of Value Chain Management, Vol. 4, No. 1-2, pp. 170-192.

Holt, R. and Barnes, C. 'Towards an integrated approach to 'design for X': an agenda for decision-based DFX research', Research in Engineering Design, Vol. 21, No. 2, pp. 123-136.

Isoherranen, V. and Kess, P. (2011) 'Analysis of strategy by strategy typology and orientation framework', Modern Economy, Vol. 2, No. 3, pp. 575-583.

Kahn, K.B. (2001) Product Planning Essentials, Sage Publications, USA.

Kahn, K.B. (Ed.), (2005) The PDMA Handbook of New Product Development, John Wiley \& Sons Inc, New Jersey, USA.

Krishnan, V. and Ulrich, K.T. (2001) 'Product development decisions: a review of the literature', Management Science, Vol. 47, No. 1, pp.1-21.

Kurk, F. and Eagan, P. (2008) 'The value of adding design-for-the-environment to pollution prevention assistance options', Journal of Cleaner Production, Vol. 16, No. 6, pp. 722-726.

Lopes, C.A. and Bolton, J.D. (2013) 'DFX - Design for Excellence at Whirlpool corporation' in Proceedings of the SAVE Value Summit 2013, pp. 130-146.

Majava, J, Harkonen, J. and Haapasalo, H. (2015) 'The relations between stakeholders and product development drivers: practitioners' perspectives', International Journal of Innovation and Learning, Vol. 17, No. 1, pp. 59-78.

Markeset, T. and Kumar, U. (2003) 'Design and development of product support and maintenance concepts for industrial systems', Journal of Quality in Maintenance Engineering, Vol. 9, No. 4, pp. 376-392.

Rungtusanatham, M. and Forza, C. (2005) 'Coordinating product design, process design, and supply chain design decisions: Part A: Topic motivation, performance implications, and article review process', Journal of Operations Management, Vol. 23, No. 3-4, pp. 257-265.

Subramani, A. and Dewhurst, P. (1993) 'Efficient design for service considerations', Manufacturing Review, Vol. 6, No. 1, pp. 40-47.

Trott, P. (2012) Innovation Management and New Product Development, Pearson Education Limited, Harlow.

Ulrich, K. and Eppinger, S.D. (2012) Product Design and Development, McGraw Hill, Singapore.

Williams, T.W. and Parker, K.P. (1982) 'Design for testability - a survey', IEEE Transactions on Computers, Vol. 31, No. 1, pp. 2-15.

Yin, R.K. (1989) Case Study Research: Design and Methods, Sage Publications, Beverly Hills, California.

Younker, J. (2008) Foundations of Agile Python Development, Apress, USA. 